\title{
Evaluation of the first-night effect of polysomnographic recording on cardiac autonomic activity in children with autism spectrum disorder
}

\author{
Erik Leonardo Mateos Salgado, ${ }^{1}$ Fructuoso Ayala Guerrero, ${ }^{1}$ Alexis de Jesús Rueda Santos, ${ }^{2}$ \\ Beatriz Eugenia del Olmo Alcántara
}

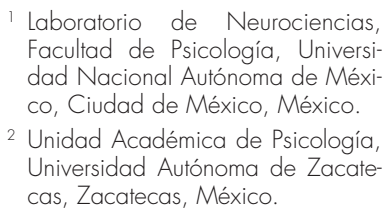

Correspondence:

Erik Leonardo Mateos Salgado Laboratorio de Neurociencias, Facultad de Psicología, Universidad Nacional Autónoma de México. Av. Universidad 3004,

04510 Coyoacán,

Ciudad de México, México.

Phone: +52 (55) 5622-2222, Ext. 41243

Email: eriklms@comunidad.unam.mx

Received: 22 December 2020

Accepted: 20 April 2021

Citation:

Mateos Salgado, E. L., Ayala Guerrero, F., Rueda Santos, A. de J., \& del Olmo Alcántara, B. E. (2021). Evalvation of the first-night effect of polysomnographic recording on cardiac autonomic activity in children with autism spectrum disorder. Salud Mental, $44(6), 307-314$

DOI: $10.17711 /$ SM.0185-3325.2021.039

\begin{abstract}
Introduction. The first night effect (FNE) is the tendency to have lower than usual sleep quality and quantity during the first polysomnography (PSG) recording, which alters sleep architecture. The FNE occurs in autism spectrum disorder (ASD), with studies suggesting that cardiac autonomic dysregulation is altered in patients with this illness. Objective. To determine whether the FNE influences the autonomic activity of ASD and typically developing (TD) children. Method. Two PSGs were recorded in 13 ASD and 13 TD children. The FNE was evaluated with eight sleep variables and autonomic activity through respiratory sinus arrhythmia (RSA) and low frequency (LF). Statistical analyses included intra- and inter-subject comparisons. Results. The FNE was present in both groups and affected more sleep variables in the ASD group. There were no significant differences between both recordings in RSA and LF. Inter-subject comparison showed significant differences in certain sleep variables, mainly during the first night. A comparison of RSA and LF between N2 and N3 stages and REM sleep showed that the TD group had significant differences in both measures whereas the ASD group only did so in the LF the first night. Discussion and conclusion. The influence of the FNE on the quantitative characteristics of sleep is corroborated in ASD and TD children, but not in RSA or LF. When the activity of the RSA and LF between sleep stages was considered, a different pattern was observed between the two PSG recordings.
\end{abstract}

Keywords: Sleep, autism, parasympathetic nervous system, heart rate variability.

\section{RESUMEN}

Introducción. El efecto de la primera noche (EPN) es la tendencia a tener una calidad y cantidad de sueño inferior a la usual durante un primer registro de polisomnografía (PSG). EI EPN se presenta en el trastorno del espectro autista (TEA) y en estos pacientes se ha propuesto que la modulación autonómica cardiaca presenta alteraciones. Objetivo. Evaluar si el EPN influye en la actividad autonómica de participantes con TEA y con desarrollo típico (DT). Método. Se realizaron dos PSGs a 13 participantes con TEA y con DT. EI EPN se evaluó con ocho variables del sueño y la actividad autonómica mediante la arritmia sinusal respiratoria (ASR) y la frecuencia-baja (LF). Los análisis estadísticos incluyeron comparaciones intra-sujeto e inter-sujeto. Resultados. EI EPN se presentó en ambos grupos y afecto más al grupo con TEA. No hubo diferencias significativas entre ambos registros en ASR y LF. De la comparación inter-sujeto hubo diferencias significativas en algunas variables del sueño, principalmente de la primera noche. Al comparar ASR y LF entre las fases N2, N3 y el sueño MOR, el grupo de DT tuvo diferencias significativas en ambas medidas, el grupo TEA solamente en LF de la primera noche. Discusión y conclusión. Se corrobora la presencia del EPN sobre las características cuantitativas del sueño en los grupos con TEA y con DT, pero no en ASR y LF. Cuando se considera la actividad de la ASR y LF entre fases de sueño se observa un patrón diferente entre los dos registros.

Palabras clave: Sueño, autismo, sistema nervioso parasimpático, variabilidad de la frecuencia cardiaca. 


\section{INTRODUCTION}

The first night effect (FNE) refers to the tendency of people to have lower quality and quantity of sleep than usual during the first polysomnography recording (PSG). This effect is thought to be the result of a lack of adaptation to the unknown environment of the sleep laboratory, as well as the discomfort caused by the electrodes and sensors required to monitor PSG physiological variables (Hirscher et al., 2015; Kupfer, Weiss, Detre, \& Foster, 1974). Although most research on the FNE has been conducted on adults, it is also present in children and adolescents (Palm, Persson, Elmqvist, \& Blennow, 1989; Scholle et al., 2003).

In general, the FNE is associated with changes in the amount and structure of sleep. Although it does not always affect the same variables, the most consistent ones are reductions in total sleep time, REM sleep time, and sleep efficiency, as well as increases in waking time, higher sleep onset, and REM sleep onset latencies (Coble, Kupfer, Taska, \& Kane, 1984; Le Bon et al., 2001; Toussaint et al., 1997; Rechtschaffen \& Verdone, 1964; Tamaki, Nittono, Hayashi, $\&$ Hori, 2005). Given the above, in sleep research, it is common practice to exclude this first PSG recording from the analyses and regard it as a process of adaptation to recording conditions. In the clinical setting, when, for several reasons, there is only one PSG recording, caution should be exercised since alterations in sleep characteristics can be associated with the presence of a disorder or disease, when in fact, the FNE would explain these alterations. It is therefore important to evaluate the FNE to identify the sleep variables that are significantly affected in a first PSG recording.

Likewise, according to researchers, analyzing the differences between the first PSG recording and subsequent ones would make it possible to evaluate people's capacity to adapt to new stressful situations (Kupfer et al., 1974; Riedel, Winfield, \& Lichstein, 2001). The FNE would therefore reflect the capacity of the organism to respond adaptively and maintain homeostasis when faced with stressors that alter sleep (Rotenberg et al., 1997). It has also been suggested that given the consequences of the FNE for sleep structure, its use as a transient insomnia model would be justified (Suetsugi, Mizuki, Yamamoto, Uchida, \& Watanabe, 2007; Toussaint et al., 1995; 1997).

Although the FNE affects certain variables of the sleep structure of children and adolescents, it does not alter other physiological variables, such as nocturnal respiratory activity (Scholle et al., 2003). In this population, the evaluation of sleep breathing disorders with a single PSG study is therefore considered adequate (Li et al., 2004; Verhulst, Schrauwen, De Backer, \& Desager, 2006). Nor does it alter electrophysiological activity patterns that make it possible to identify certain pathologies such as the continuous pattern of spikes and waves in slow sleep present in certain patients at night (Veggiotti, Beccaria, Guerrini, Capovilla, \& Lanzi, 1999).
At the same time, autism spectrum disorder (ASD) is considered a behavioral syndrome of neurological origin, characterized by deficits in social interaction, difficulty in establishing links and understanding the mental states of other people, difficulty in verbal and non-verbal communication, and repetitive or stereotyped behavior patterns (Volkmar, 2013). In ASD, there is a high prevalence of difficulty in the initiation and maintenance of sleep, a decrease in sleep efficiency, total sleep time, the percentage of time in slow wave sleep and REM sleep, as well as increases in wakefulness after sleep onset (Ayala-Guerrero, Mexicano, \& Mateos, 2020; Hodge, Parnell, Hoffman, \& Sweeney, 2012; Kotagal \& Broomall, 2012; Paavonen et al., 2008). In relation to the FNE in ASD, one study found reductions in sleep efficiency and the duration of the N2 stage, together with an increase in the amount of wakefulness once sleep has begun (Buckley et al., 2013).

It has been posited that in ASD, modulation of the autonomic nervous system (ANS) could experience some dysregulation (Porges, 2007; Tessier, Pennestri, \& Godbout, 2018). Within this context, a non-invasive method has been suggested to assess the autonomic regulation of cardiac activity, especially the involvement of the parasympathetic nervous system (PNS), by analyzing the length of the intervals between each heartbeat and heart rate variability (HRV) (Laborde, Mosley, \& Thayer, 2017). HRV in ASD has usually been analyzed while the subject is awake to evaluate various situations such as stress reactivity, social involvement, and cognitive tasks (Cheng, Huang, \& Huang, 2020), whereas the evaluation of HRV during sleep in ASD is less common (Harder et al., 2016; Pace, Dumortier, Favre-Juvin, Guinot, \& Bricout, 2016; Tessier et al., 2018). In these studies, HRV was analyzed on different days, but FNE was not evaluated.

Evaluating the FNE has proven to be an effective way to determine people's ability to adapt to changes in their sleeping environment. The purpose of this study was to analyze the FNE to assess the adaptability of participants with ASD and a group with typical development (TD), in addition to evaluating the influence of the FNE on the autonomic regulation of the heart analyzed by HRV.

\section{METHOD}

\section{Study design}

An analytical cross-sectional case-control study was conducted.

\section{Subjects}

Using non-probabilistic convenience sampling, male subjects with an ASD diagnosis referred by various associa- 
tions, foundations, and hospital centers were selected. The initial sample consisted of 15 children who met the diagnostic criteria for Level 1 or 2 autism spectrum disorder (mild to moderate) according to the Diagnostic and Statistical Manual of Mental Disorders, 5th edition (DSM-5, 2013). Since two subjects failed to complete the second PSG recording, the final sample consisted of 13 children with a mean age of $8.8(S D$ standard deviation $=1.5)$ years. Thirteen children with TD with an average age of $9(S D=$ 1.8) also participated. None of the participants was under pharmacological treatment during the PSG recordings. The exclusion criteria for both groups were having an IQ of less than 80; a clinical history reporting the presence of a genetic syndrome; and the diagnosis of a neurological or psychiatric disease.

\section{Place}

The PSG recordings were made in the neuroscience laboratory of the National Autonomous University of Mexico (Universidad Nacional Autónoma de México, UNAM) Psychology Faculty.

\section{Procedure}

Two PSGs were performed on consecutive nights for each participant. The first PSG included the recording of the electroencephalogram (EEG) in the $\mathrm{F} 3, \mathrm{C} 3, \mathrm{O} 1, \mathrm{~F} 4, \mathrm{C} 4$, and $\mathrm{O} 2$ leads with contralateral references in the right and left mastoid bones, respectively; an electrooculogram (EOG); an electromyogram (EMG) of the mentalis muscle and the left and right anterior tibilialis; an electrocardiogram (ECG); the oxygen saturation percentage; and breathing measured by an oronasal flow thermistor and thoracic and abdominal respiratory effort bands. The second PSG included the recording of an EEG in the F3, C3, P3, O1, T3, F4, C4, $\mathrm{P} 4, \mathrm{O} 2$, and T4 leads with contralateral references; an EOG; an EMG of the mentalis muscle; and an ECG. The start of each PSG recording (with the lights off) was adjusted to the usual sleep schedule of each subject and the duration of the recording was approximately eight hours. The sampling frequency of all the recorded signals was $400 \mathrm{~Hz}$ and the notch filter was set at $60 \mathrm{~Hz}$.

\section{Measurements}

Sleep was rated according to the rules established in the American Academy of Sleep Medicine Manual (Iber, Ancoli-Israel, Chesson, \& Quan, 2007). The following variables were measured: total length of each sleep stage, amount of wakefulness after sleep onset (WASO), sleep efficiency, sleep latency, and REM sleep latency. Sleep latency was defined as the time between the beginning of the recording (turning off the lights) and the first epoch of the
N1 stage of NREM sleep; REM latency was defined as the time between the first epoch of sleep and the first epoch of REM sleep. Moreover, the first PSG recording permitted the exclusion of subjects with sleep-disordered breathing or periodic limb movement that could affect the objectives of the study.

\section{Statistical analysis}

\section{HRV analysis}

Samples of cardiac activity from stages N2, N3, and REM sleep were selected. Each sample had a duration of five minutes, with no presence of motion artifacts or cortical arousals. QRSTool software version 1.2.2 (Allen, Chambers, \& Towers, 2007) was used to obtain the intervals between each heartbeat. CardioBatch Plus software (Brain-Body Center for Psychophysiology and Bioengineering, University of North Carolina) was subsequently employed to obtain respiratory sinus arrhythmia (RSA) in the .12-1 Hz band and low frequency (LF) in the .06-.1 Hz band.

\section{Intra-subject analysis}

Because certain variables in both groups did not have normal distribution, and the sample size in both groups, it was decided to use non-parametric tests. The two PSG recordings were compared using the Wilcoxon signed-rank test in each group to evaluate the presence of the FNE. To ensure that total recording time was the same in both PSGs, the number of recording times was equalized based on the PSG with fewer times.

In addition, the characteristics of the HRV measurements between NREM sleep (stages N2 and N3) and REM sleep were evaluated using the Friedman test for each group. The level of significance was expressed as $p<.05$. In the case of statistically significant results, post-hoc analyses of the N2-N3, N2-REM, and N3-REM pairs were added to the Wilcoxon signed-rank test. For these analyses, the level of significance was expressed as $p<.017$.

\section{Inter-subject analysis}

Using the Mann-Whitney $U$ test, the groups with ASD and TD were compared as regards the sleep variables and HRV measurements; each PSG recording was separately analyzed. The significance level was expressed as $p<.05$.

\section{Ethical considerations}

Information on the PSG procedure was provided in both groups and, once the children had agreed to participate in the study, their parents or guardians signed an informed consent letter. All study procedures were performed in accordance with the Declaration of Helsinki. The Research Ethics Committee of the UNAM Psychology Faculty, number FPSI/422/CEIP/582/2018, endorsed this research. 
Table 1

Comparison of both $P S G$ recordings in the group with $A S D$

\begin{tabular}{lclcccc}
\hline & \multicolumn{1}{c}{ PSG 1 } & \multicolumn{1}{c}{ PSG 2 } & Z & $p$ \\
\hline TT N1 (min) & 41 & $(25-68.5)$ & 25.5 & $(22.3-35)$ & -1.99 & .046 \\
TT N2 (min) & 164 & $(133.2-212)$ & 219.5 & $(192-263.2)$ & -2.97 & .003 \\
TT N3 (min) & 105 & $(90.2-117.2)$ & 128 & $(97.5-145)$ & -2.27 & .023 \\
TT REM (min) & $48.5(29.8-56)$ & 65 & $(58.5-88.7)$ & -3.10 & .002 \\
Sleep latency (min) & $24.5(16-41)$ & $8.5(7.8-18.3)$ & -2.04 & .041 \\
REM Sleep latency (min) & 177 & $(127.3-239)$ & 179 & $(163.3-205)$ & -.38 & $\mathrm{~ns}$ \\
WASO (min) & 56 & $(32.5-124.8)$ & 3 & $(1-4.5)$ & -3.18 & .001 \\
Sleep efficiency (\%) & 84 & $(66-88.5)$ & 96 & $(95-98)$ & -3.11 & .002 \\
RSA N2 (In) & $7.4(6.9-8.1)$ & $7.4(6.7-8.6)$ & -.79 & $\mathrm{~ns}$ \\
RSA N3 (In) & 7 & $(6.5-7.7)$ & $7.5(6.6-8.3)$ & -.98 & $\mathrm{~ns}$ \\
RSA REM (In) & 8 & $(6.4-8.6)$ & $7.4(6.6-8.3)$ & -1.58 & $\mathrm{~ns}$ \\
LF N2 (In) & 4 & $(3.8-5)$ & 4 & $(3.5-5.3)$ & -.35 & $\mathrm{~ns}$ \\
LF N3 (In) & $3.6(3.4-4.3)$ & 4 & $(3.5-4.9)$ & -1.93 & $\mathrm{~ns}$ \\
LF REM (In) & $4.9(4-5.8)$ & $4.5(4.1-5.2)$ & -1.61 & $\mathrm{~ns}$ \\
\hline
\end{tabular}

Notes: median (Percentile 25-Percentile 75); ns = not significant; TT = total time; WASO = wakefulness after sleep onset; RSA = respiratory sinus arrhythmia; LF = low frequency; In = natural logarithm.

\section{RESULTS}

\section{Sleep variables}

No sleep-related breathing disorders or periodic limb movement were identified in either group. In the group with ASD, in the first PSG, the means of the total times were $45.85 \mathrm{~min}$ (Standard deviation $[S D]=21.9$ ) in stage N1, $171.3 \mathrm{~min}$ $(S D=50.2)$ in stage $\mathrm{N} 2,104.2 \mathrm{~min}(S D=19.6)$ in stage $\mathrm{N} 3$ and $45.8 \mathrm{~min}(S D=18.2)$ of REM sleep. In the second PSG, the means were $29.2 \mathrm{~min}(S D=10.9)$ of stage N1, 226.8 $\min (S D=41.3)$ of stage $\mathrm{N} 2,122.3 \mathrm{~min}(S D=28.6)$ of stage $\mathrm{N} 3$ and $72.9 \min (S D=23.4)$ of REM sleep.

Conversely, in the group with TD, the means of the total times were $41.2 \min (S D=12.2)$ in stage $\mathrm{N} 1,220 \mathrm{~min}$
$(S D=22.8)$ in stage $\mathrm{N} 2,109.6 \mathrm{~min}(S D=22.7)$ in stage N3 and $76.7 \mathrm{~min}(S D=17)$ of REM sleep. In the second PSG, the means were $24.2 \mathrm{~min}(S D=6.7)$ in stage $\mathrm{N} 1,221.4 \mathrm{~min}$ $(S D=21.8)$ in stage $\mathrm{N} 2,122.3 \mathrm{~min}(S D=16.1)$ in stage $\mathrm{N} 3$ and $94.3 \mathrm{~min}(S D=17.4)$ in REM sleep.

In the group of children with ASD, except for the REM sleep onset latency, statistically significant differences were found in the sleep variables analyzed (Table 1). In the first PSG recording, there was greater sleep onset latency and a longer stage N1 and WASO. Moreover, in the first PSG, sleep efficiency was lower and the N2, N3, and REM sleep stages were shorter.

Unlike the group with ASD, in the group with TD, statistically significant differences were only found in four sleep variables (Table 2). In the first PSG recording, there was a

Table 2

Comparison between both PSG recordings in group with $T D$

\begin{tabular}{lclcccc}
\hline & \multicolumn{2}{c}{ PSG 1 } & \multicolumn{2}{c}{ PSG 2 } & Z & $p$ \\
\hline TT N1 (min) & \multicolumn{2}{c}{$40.5(28-50.8)$} & 22.5 & $(18.8-29.3)$ & -3.18 & .001 \\
TT N2 (min) & 217 & $(200-241)$ & 213 & $(204.8-243)$ & -.18 & $\mathrm{~ns}$ \\
TT N3 (min) & $112.5(95-126)$ & 121.5 & $(110-134.3)$ & -1.65 & $\mathrm{~ns}$ \\
TT REM (min) & 82 & $(62.3-90.5)$ & 89.5 & $(83-110)$ & -2.62 & .009 \\
Sleep latency (min) & $12.5(7.3-26.3)$ & 7 & $(4-19.3)$ & -.84 & $\mathrm{~ns}$ \\
REM sleep latency (min) & 149 & $(132-230.3)$ & 89.5 & $(70-136.5)$ & -2.93 & .003 \\
WASO (min) & 12 & $(4.5-31)$ & $5.5(3-7)$ & -2.38 & .017 \\
Sleep efficiency (\%) & 94 & $(88.5-98)$ & 97 & $(95-98)$ & -1.49 & $\mathrm{~ns}$ \\
RSA N2 (In) & $7.6(6.7-8.3)$ & $7.6(7-8.4)$ & -.71 & $\mathrm{~ns}$ \\
RSA N3 (In) & $7.3(6.6-8.1)$ & $7.6(7-8.2)$ & -.53 & $\mathrm{~ns}$ \\
RSA REM (In) & $7.5(6.9-8.3)$ & $7.8(7.1-8.3)$ & -.46 & $\mathrm{~ns}$ \\
LF N2 (In) & $4.1(3.3-4.8)$ & 4 & $(3.8-5)$ & -.47 & $\mathrm{~ns}$ \\
LF N3 (In) & $3.9(2.6-4.2)$ & $3.8(3.3-4.2)$ & -.79 & $\mathrm{~ns}$ \\
LF REM (In) & $4.5(4-5.5)$ & 5 & $(4.4-5.3)$ & -.45 & $\mathrm{~ns}$ \\
\hline
\end{tabular}

Notes: median (Percentile 25-Percentile 75); ns = not significant; TT = total time; WASO = wakefulness after sleep onset; RSA = respiratory sinus arrhythmia; LF = low frequency; In = natural logarithm. 


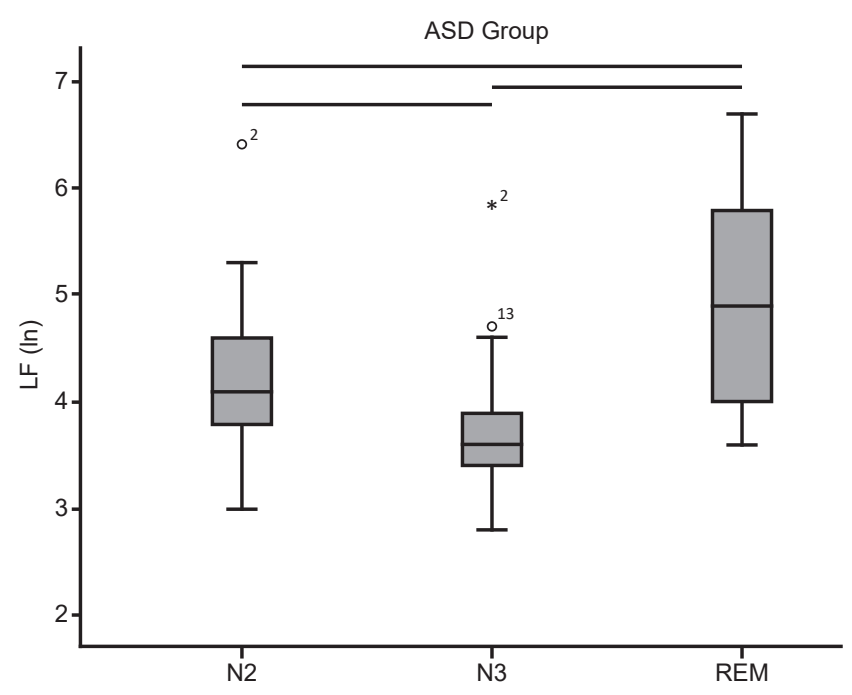

Figure 1. Box plot of post-hoc comparison of LF between N2-N3, N2-REM and N3-REM peers in the first PSG record in the group with ASD. The lines show statistically significant results with $p<.017$.

longer stage N1 and WASO, and longer REM sleep onset latency. REM sleep time was also shorter in the first PSG.

The inter-subject comparison found that in the first PSG recording, the group with ASD spent less time in the N2 stage $(U=33, p=.008)$ and REM sleep $(U=18, p=.001)$ and had lower sleep efficiency $(U=26.5, p=.003)$ and higher WASO $(U=25, p=.002)$. In the second PSG recording, the group with ASD had shorter REM sleep time $(U=34, p=.01)$ and longer REM sleep onset latency $(U=13, p<.001)$.

\section{HRV measurements}

In the group with ASD, no statistically significant differences were found between the two PSG recordings in the RSA and LF measurements (Table 1) or between both recordings in these two measures (Table 2) in the group with TD either.

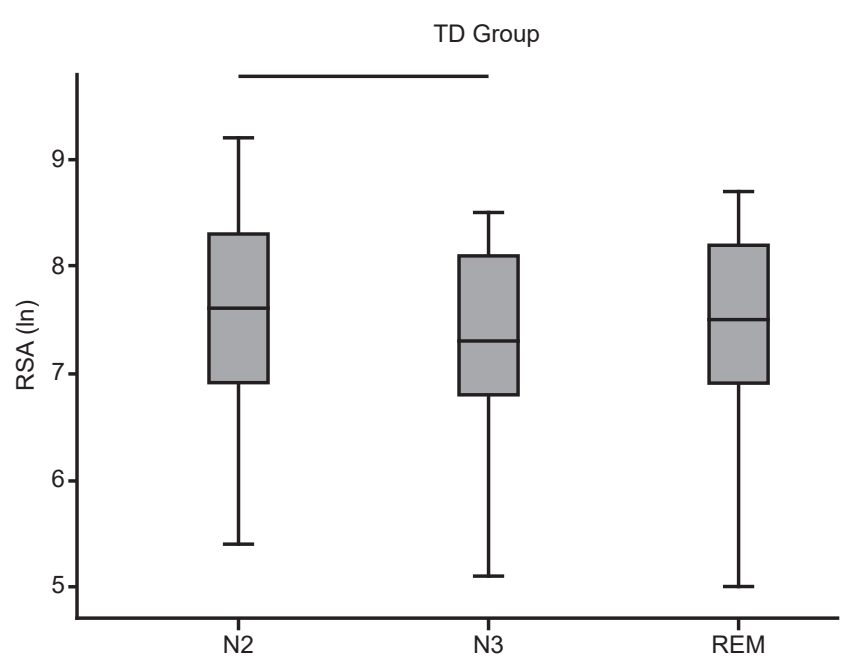

Figure 2. Box plot of post-hoc comparison of RSA between N2-N3, N2-REM and N3-REM peers of first PSG record in the group with TD. The line shows the statistically significant result with $p<.017$.

In the inter-subject comparison, statistically significant differences were not found in either of the HRV measurements in both PSG recordings.

In the comparison between NREM and REM sleep using the Friedman test, in the group with ASD, there was only one statistically significant difference in the first PSG recording in LF (Chi square $=18, p<.001)$. The post-hoc analysis found statistically significant differences in the three pairs N2-N3, N2-REM, and N3-REM, with the LF value being lower in the N3 stage and higher in REM sleep (Figure 1).

In the group with $\mathrm{TD}$, in the comparison between NREM and REM sleep, statistically significant differences were found in RSA (Chi square $=9.48, p=.009)$ and LF $(\mathrm{Chi}$ square $=20.59, p<.001)$ in the first PSG recording, as well as in LF in the second PSG recording (Chi square $=20.04$, $p<.001)$. In RSA with the post-hoc analysis, it was found

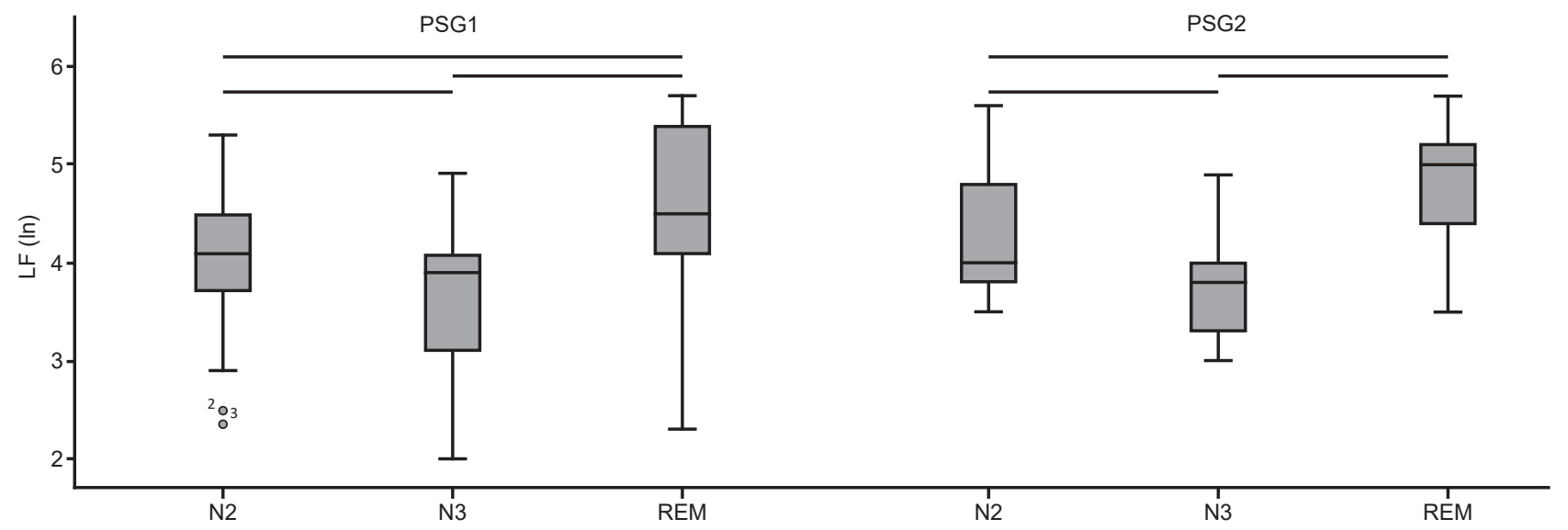

Figure 3. Box plots of post-hoc comparisons of LF between N2-N3, N2-REM and N3-REM peers between both records of PSG in the group with TD. The lines show statistically significant results with $p<.017$. 
that only the N2-N3 pair significantly differed, with a higher value in the N2 stage (Figure 2). In LF with post-hoc analysis, statistically significant differences were found in the three N2-N3, N2-REM, and N3-REM, pairs in both PSG recordings, with a higher value in REM sleep and a lower value in the N3 stage (Figure 3).

\section{DISCUSSION AND CONCLUSION}

In studies analyzing the FNE effect, similar PSG montages are used in the recordings of the first and subsequent nights (Li et al., 2004). The use of different montages to obtain the PSG does not influence the quantitative or qualitative characteristics of sleep (Hirshkowitz, 2017). This study found that the use of two different montages did not influence the FNE, since both groups displayed worse values in the sleep variables in the first PSG recording. The first montage used in this study made it possible to identify the presence of a sleep disorder in certain participants and exclude it to avoid distorting the data obtained (Verhulst et al., 2006).

The FNE in the group of patients with ASD was more evident than in the group with TD. Both groups showed higher amounts of WASO in the first recording, while the amount of REM sleep was lower. These findings confirm that the FNE consistently affects these two variables (Coble et al., 1984; Palm et al., 1989; Scholle et al., 2003; Verhulst et al., 2006), which explains why subjects in the group with ASD displayed a process of adaptation to the PSG recording like that of the group with TD. Although the FNE influenced a smaller amount of REM sleep in the first PSG recording of both groups, statistically significant differences were found in the inter-subject comparison in both recordings, such that a smaller amount of REM sleep would be a characteristic of the sleep structure altered by the presence of ASD.

REM sleep latency is another variable that the FNE consistently affects. In the group with TD, this variable was significantly smaller in the second PSG, whereas it failed to display any statistically significant changes in the group with ASD. The reduction of this latency in the group with TD sufficed to significantly distinguish it from the group with ASD in the second PSG recording. Studies have reported that REM sleep latency differs between patients with ASD and control groups with TD and is usually longer in patients (Cebreros-Paniagua, Ayala-Guerrero, \& Mateos-Salgado, 2020; Giannotti, Cortesi, Cerquiglini, Vagnoni, \& Valente, 2011; Miano et al., 2007), while others have found no differences between the two groups (Bruni et al., 2007; Malow et al., 2006). Since this variable did not change in the group with ASD between both PSG recordings, then the FNE can be said not to alter REM sleep latency in this type of patient.

In the group with ASD, the FNE affected four other sleep variables, leading to lower sleep efficiency and a shorter N2 stage. These variables were also significantly lower than those of the TD group on the first night of recording. These data suggest that patients are more sensitive to the FNE, but show adequate adaptation to recording conditions, achieving similar values to the group with TD on the second night of recording, as described in a study conducted on patients with ASD (Buckley et al., 2013). Likewise, it has been reported that only in the first PSG recording is sleep efficiency lower in the group with ASD compared to the control group (Malow et al., 2006).

Of the HRV measures analyzed, RSA is considered an indicator of PNS activity and is related to cardiorespiratory coupling, a measure sometimes known as high frequency (HF) (Laborde et al., 2017). There is some controversy about the functional role of the LF measure. The most robust proposal is related to the mechanisms to control PNS on blood pressure through the regulation of vasomotor tone and baroreceptor activity (Reyes del Paso, Langewitz, Mulder, van Roon, \& Duschek, 2013).

Neither of the groups studied showed any statistically significant differences between the two PSG recordings for RSA and LF, meaning that the FNE did not influence these measures, suggesting that during sleep, these physiological variables remain constant to maintain a balance of the vegetative functions of the organism. This is further supported by the fact that there were no statistically significant differences in the intergroup comparison for each night of recording, which coincides with a study in which the HF and LF measurements were evaluated during a second PSG recording of patients with ASD and another group with TD, although in this study, only stage N2 and REM sleep were analyzed (Tessier et al., 2018).

In a study by Harder et al. (2016), there was only one PSG recording and when the HF and LF measures were evaluated, statistically significant differences were found between a group with ASD and a group with TD during the N3 and REM sleep stages. However, in this study, the age range of subjects was different, oscillating between 4 and 10 years, and the HF measurement used the frequency range of $.15-.40 \mathrm{~Hz}$. Since HF and RSA are associated with cardiorespiratory and PNS activity, the frequency range should be adjusted to take the breathing rate into account (Berntson et al., 1997). Our study used the $.12-1 \mathrm{~Hz}$ range, which considers the influence of the higher breathing rate typical of children and adolescents (Wallis, Healy, Undy, \& Maconochie, 2005).

How the ANS works varies according to the type and depth of sleep. During NREM sleep, there is a predominance of parasympathetic activity and a decrease in sympathetic activity, whereas in REM sleep, there is a predominance of sympathetic activity and fluctuations in parasympathetic activity (Lanfranchi, Pépin, \& Somers, 2017). Consequently, studies analyzing HRV during sleep usually compare HRV measurements between NREM and REM sleep (Stein \& Pu, 2012). In this study, the N1 stage of NREM sleep was not 
included because few participants experienced it for over five minutes continuously, which is common during this sleep stage (Carskadon \& Dement, 2017).

In the group with TD, the pattern of LF activity between NREM and REM sleep was similar between both PSG recordings, since the LF values followed the same tendency to display statistically significant differences in the three pairs analyzed (N2-N3, N2-REM, and N3-REM). Accordingly, in this group, the FNE did not alter the LF activity pattern. However, in the group with ASD, there were discrepancies between both PSG recordings in the LF pattern between NREM and REM sleep, although in LF, there were no statistically significant differences between the two PSG recordings.

Likewise, in the group with TD, there were discrepancies between both PSG recordings in the pattern of RSA activity between NREM and REM sleep. In the first PSG recording, RSA was significantly lower in the N3 than the N2 stage. This reduction in RSA in stage N3 could be attributed to the stress associated with the first PSG recording (Rotenberg et al., 1997), since RSA values in stage N3 are stable on different nights (Herzig et al., 2018) and RSA is reduced in the presence of various stressors (Kim, Cheon, Bai, Lee, \& Koo, 2018). However, the RSA values of stage N3 did not significantly differ between the two PSG recordings.

Since no statistically significant differences were found between the two recordings in RSA and LF, it is not possible to clearly determine the influence of the FNE on the activity patterns arising from the comparison between NREM and REM sleep. These results cannot be contrasted with previous results, due to the lack of studies in the literature consulted on the relationship between the FNE and the autonomic regulation of cardiac activity evaluated by HRV, in both patients with ASD and groups with TD. The limitations of this study include the small sample size and the fact that only subjects with mild to moderate ASD were evaluated.

The results obtained in this study confirm that the FNE is expressed in sleep architecture and its quantitative characteristics. In subjects with ASD, the FNE influenced more sleep variables. The values obtained from the PSG of a single night must therefore be considered with caution to distinguish the FNE on sleep from that caused by the neurodevelopmental disease itself, even though subjects with ASD displayed an adequate capacity to adapt to the conditions associated with the PSG recordings. As for HRV, this would seem to be another type of physiological variable that is not altered by FNE. However, additional studies are required given the need to determine whether the FNE influences the pattern of HRV activity between NREM and REM.

\section{Financing}

This study was financed by the IG200619 DGAPA-PAPIIT project, UNAM, Mexico.

\section{Conflict of interest}

The authors declare that they have no conflicts of interest.

\section{Acknowledgements}

We would like to thank the Caritas de Amistad AC foundation and the neuroscience laboratory staff who took part in the PSG recordings.

\section{REFERENCES}

Allen, J. J. B., Chambers, A. S., \& Towers, D. N. (2007). The many metrics of cardiac chronotropy: A pragmatic primer and a brief comparison of metrics. Biological Psychology, 74(2), 243-262. doi: 10.1016/j.biopsycho.2006.08.005

Ayala-Guerrero, F. Mexicano, G., \& Mateos, E. L., (2020). Sleep disturbances in autistic spectrum disorder (ASD) patients. In I. Ramírez Salado, A. P. Rivera García, \& M. A. Cruz Aguilar (Eds.). Sleep cognition and emotion: from molecules to social ecology (pp. 245-274). New York: Nova Science Publishers, Inc.

Berntson, G. G., Bigger Jr., J. T., Eckberg, D. L., Grossman, P., Kaufmann, P. G., Malik, M., ... vander Molen, M. W. (1997). Heart rate variability: Origins, methods, and interpretive caveats. Psychophysiology, 34(6), 623-648. doi: 10.1111/j.1469-8986.1997.tb02140.x

Bruni, O., Ferri, R., Vittori, E., Novelli, L., Vignati, M., Porfirio, M. C., ... Curatolo, P. (2007). Sleep architecture and NREM alterations in children and adolescents with Asperger syndrome. Sleep, 30(11), 1577-1585. doi: 10.1093/ sleep/30.11.1577

Buckley, A., Wingert, K., Swedo, S., Thurm, A., Sato, S., Appel, S., ... Rodriguez, A. J. (2013). First night effect analysis in a cohort of young children with autism spectrum disorder. Journal of Clinical Sleep Medicine, 9(1), 67-70. doi: $10.5664 / \mathrm{jcsm} .2344$

Carskadon, M. A., \& Dement, W. C. (2017). Normal human sleep: An overview. In M. H. Kryger, T. Roth, \& W. C. Dement (Eds.). Principles and Practice of Sleep Medicine (pp. 142-154). Philadelphia: Elsevier.

Cebreros-Paniagua, R., Ayala-Guerrero, F., \& Mateos-Salgado, E. L. (2020). Sleep disturbances in patients with Asperger syndrome related to the severity of their symptoms. Sleep and Vigilance, 4(2), 161-166. doi: 10.1007/s41782-02000104-6

Cheng, Y.-C., Huang, Y.-C., \& Huang, W.-L. (2020). Heart rate variability in individuals with autism spectrum disorders: A meta-analysis. Neuroscience \& Biobehavioral Reviews, 118, 463-471. doi: 10.1016/j.neubiorev.2020.08.007

Coble, P. A., Kupfer, D. J., Taska, L. S., \& Kane, J. (1984). EEG sleep of normal healthy children. Part I: findings using standard measurement methods. Sleep, 7(4), 289-303. doi: 10.1093/sleep/7.4.289

Giannotti, F., Cortesi, F., Cerquiglini, A., Vagnoni, C., \& Valente, D. (2011). Sleep in children with autism with and without autistic regression. Journal of Sleep Research, 20(2), 338-347. doi: 10.1111/j.1365-2869.2010.00882.x

Harder, R., Malow, B. A., Goodpaster, R. L., Iqbal, F., Halbower, A., Goldman, S. E., ... Diedrich, A. (2016). Heart rate variability during sleep in children with autism spectrum disorder. Clinical Autonomic Research, 26(6), 423-432. doi: 10.1007/s10286-016-0375-5

Herzig, D., Eser, P., Omlin, X., Riener, R., Wilhelm, M., \& Achermann, P. (2018). Reproducibility of heart rate variability is parameter and sleep stage dependent. Frontiers in Physiology, 8, 1100. doi: 10.3389/fphys.2017.01100

Hirscher, V., Unbehaun, T., Feige, B., Nissen, C., Riemann, D., \& Spiegelhalder, K. (2015). Patients with primary insomnia in the sleep laboratory: do they present with typical nights of sleep? Journal of Sleep Research, 24(4), 383-389. doi: $10.1111 /$ jsr. 12280

Hirshkowitz, M. (2017). Polysomnography and beyond. In M. H. Kryger, T. Roth, \& W. C. Dement (Eds.). Principles and Practice of Sleep Medicine (pp. 15641566). Philadelphia: Elsevier.

Hodge, D., Parnell, A. M. N., Hoffman, C. D., \& Sweeney, D. P. (2012). Methods for assessing sleep in children with autism spectrum disorders: A review. Research in Autism Spectrum Disorders, 6(4), 1337-1344. doi: 10.1016/j. rasd.2012.05.009 
Iber, C., Ancoli-Israel, S., Chesson, A. L., \& Quan, S. F. (2007). The AASM Manual for the Scoring of Sleep and Associated Events: Rules, Terminology and Technical Specifications. Illinois, USA: American Academy of Sleep Medicine.

Kim, H.-G., Cheon, E.-J., Bai, D.-S., Lee, Y. H., \& Koo, B.-H. (2018). Stress and heart rate variability: A meta-analysis and review of the literature. Psychiatry Investigation, 15(3), 235-245. doi: 10.30773/pi.2017.08.17

Kotagal, S., \& Broomall, E. (2012). Sleep in children with autism spectrum disorder. Pediatric Neurology, 47(4), 242-251. doi: 10.1016/j.pediatrneurol.2012.05.007

Kupfer, D. J., Weiss, B. L., Detre, T. P., \& Foster, G. F. (1974). Firstnighteffectrevisited: a clinical note. The Journal of Nervous and Mental Disease, 159(3), 205-209. doi: 10.1097/00005053-197409000-00009

Laborde, S., Mosley, E., \& Thayer, J. F. (2017). Heart rate variability and cardiac vagal tone in psychophysiological research.Recommendations for experiment planning, data analysis, and data reporting. Frontiers in Psychology, 8, 213. doi: 10.3389/fpsyg.2017.00213

Lanfranchi, P. A., Pépin, J., \& Somers, V. K. (2017). Cardiovascular physiology: autonomic control in health and in sleep disorders. In M. H. Kryger, T. Roth, \& W. C. Dement (Eds.). Principles and Practice of Sleep Medicine (pp. 142-154). Philadelphia: Elsevier.

Le Bon, O., Staner, L., Hoffmann, G., Dramaix, M., San Sebastian, I., Murphy, J.R., ... Linkowski, P. (2001). The first-night effect may last more than one night. Journal of Psychiatric Research, 35(3), 165-172. doi: 10.1016/S00223956(01)00019-X

Li, A. M., Wing, Y. K., Cheung, A., Chan, D., Ho, C., Hui, S., \& Fok, T. F. (2004). Is a 2-night polysomnographic study necessary in childhood sleep-related disordered breathing? Chest, 126(5), 1467-1472. doi: 10.1378/chest.126.5.1467

Malow, B. A., Marzec, M. L., McGrew, S. G., Wang, L., Henderson, L. M., \& Stone, W. L. (2006). Characterizing sleep in children with autism spectrum disorders: amultidimensional approach. Sleep, 29(12), 1563-1571. doi: 10.1093/ sleep/29.12.1563

Miano, S., Bruni, O., Elia, M., Trovato, A., Smerieri, A., Verrillo, E., ... Ferri, R. (2007). Sleep in children with autistic spectrum disorder: A questionnaire and polysomnographic study. Sleep Medicine, 9(1), 64-70. doi: 10.1016/j. sleep.2007.01.014

Paavonen, E. J., Vehkalahti, K., Vanhala, R., von Wendt, L., Nieminen-von Wendt, T., \& Aronen, E. T. (2008). Sleep in Children with Asperger Syndrome. Journal of Autism and Developmental Disorders, 38(1), 41-51. doi: 10.1007/s10803007-0360-x

Pace, M., Dumortier, L., Favre-Juvin, A., Guinot, M., \& Bricout, V.-A. (2016). Heart rate variability during sleep in children with autism spectrum disorders. Physiology \& Behavior, 167, 309-312. doi: 10.1016/j.physbeh.2016.09.027

Palm, L., Persson, E., Elmqvist, D., \& Blennow, G. (1989). Sleep and wakefulness in normal preadolescent children. Sleep, 12(4), 299-308. doi: 10.1093/ sleep/12.4.299

Porges, S. W. (2007). The polyvagal perspective. Biological Psychology, 74(2), 116143. doi: 10.1016/j.biopsycho.2006.06.009

Rechtschaffen, A., \& Verdone, P. (1964). Amount of dreaming;effect of incentiveadaptation to laboratory, and individual differences. Perceptual and Motor Skills, 19(3), 947-958. doi: 10.2466/pms.1964.19.3.947
Reyes del Paso, G. A., Langewitz, W., Mulder, L. J. M., van Roon, A., \& Duschek, S. (2013). The utility of low frequency heart rate variability as an index of sympathetic cardiac tone: A review with emphasis on analysis of previous studies. Psychophysiology, 50(5), 477-487. doi: 10.1111/psyp.12027

Riedel, B. W., Winfield, C. F., \& Lichstein, K. L. (2001). First night effect and reverse first night effect in older adults with primary insomnia: does anxiety play a role? Sleep Medicine, 2(2), 125-133. doi: 10.1016/s1389-9457(00)00054-x

Rotenberg, V. S., Hadjez, J., Kimhi, R., Indurski, P., Sirota, P., Mosheva, T., ... Elizur, A. (1997). First night effect in depression: New data and a new approach. Biological Psychiatry, 42(4), 267-274. doi: 10.1016/S0006-3223(96)00343-5

Scholle, S., Scholle, H.-C., Kemper, A., Glaser, S., Rieger, B., Kemper, G., \& Zwacka, G. (2003). First night effect in children and adolescents undergoing polysomnography for sleep-disordered breathing. Clinical Neurophysiology, 114(11), 2138-2145. doi: 10.1016/s1388-2457(03)00209-8

Stein, P. K., \& Pu, Y. (2012). Heart rate variability, sleep and sleep disorders. Sleep Medicine Reviews, 16(1), 47-66. doi: 10.1016/j.smrv.2011.02.005

Suetsugi, M., Mizuki, Y., Yamamoto, K., Uchida, S., \& Watanabe, Y. (2007). The effect of placebo administration on the first-night effect in healthy young volunteers. Progress in Neuro-Psychopharmacology and Biological Psychiatry, 31(4), 839-847. doi: 10.1016/j.pnpbp.2007.01.019

Tamaki, M., Nittono, H., Hayashi, M., \& Hori, T. (2005). Examination of the firstnight effect during the sleep-onset period. Sleep, 28(2), 195-202. doi: 10.1093/ sleep/28.2.195

Tessier, M. P., Pennestri, M. H., \& Godbout, R. (2018). Heart rate variability of typically developing and autistic children and adults before, during and after sleep. International Journal of Psychophysiology, 134, 15-21. doi: 10.1016/j. ijpsycho.2018.10.004

Toussaint, M., Luthringer, R., Schaltenbrand, N., Carelli, G., Lainey, E., Jacqmin, A., ... Macher, J.-P. (1995). First-night effect in normal subjects and psychiatric inpatients. Sleep, 18(6), 463-469. doi: 10.1093/sleep/18.6.463

Toussaint, M., Luthringer, R., Schaltenbrand, N., Nicolas, A., Jacqmin, A., Carelli, G., ... Macher, J.-P. (1997). Changes in EEG power density during sleep laboratory adaptation. Sleep, 20(12), 1201-1207. doi: 10.1093/sleep/20.12.1201

Veggiotti, P., Beccaria, F., Guerrini, R., Capovilla, G., \& Lanzi, G. (1999). Continuous spike-and-wave activity during slow-wave sleep: syndrome or EEG pattern? Epilepsia, 40(11), 1593-1601. doi: 10.1111/j.1528-1157.1999.tb02045.x

Verhulst, S. L., Schrauwen, N., De Backer, W. A., \& Desager, K. N. (2006). First night effect for polysomnographic data in children and adolescents with suspected sleep disordered breathing. Archives of Disease in Childhood, 91(3), 233-237. doi: 10.1136/adc.2005.085365

Volkmar, F. R. (2013). Encyclopedia of autism spectrum disorders. EUA: Springer Science.

Wallis, L. A., Healy, M., Undy, M. B., \& Maconochie, I. (2005). Age related reference ranges for respiration rate and heart rate from 4 to 16 years. Archives of Disease in Childhood, 90(11), 1117-1121. doi: 10.1136/adc.2004.068718 